peritonitis, or a condition which is a prelude to that, possibly pneumococcal. The condition cleared up in twenty-four hours on a powder of calomel gr. 1/8, sodium salicylate gr. 2, bismuth carbonate gr. 3 . The implication of the nervous system is probably more intense in such infections.

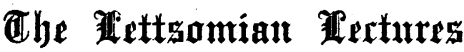

on

\section{AMOEBIC LIVER ABSCESS.}

Delivered Before the Medical Society of LoNdoN

BY

Sir LEONARD ROGERS, C.I.E., M.D., F.R.S.

[Abstract.]

Lecture I.-Etiology and Pathology.

Sir Leonard Rogers began by saying that when he received the invitation to deliver the Lettsomian Lectures he cast about in his mind for a subject from among the many diseases which he had been investigating during his twenty-seven years of research in India. In view of the fact that he had been awarded the Fothergillian medal of the society for his work on amoebic diseases, he came to the conclusion that he might suitably deal with amoebic hepatitis, more especially as the late Dr. Sandwith had ably dealt with dysentery in the Lettsomian Lectures of 1914. The present course, therefore, would be complementary to that given by Dr. Sandwith, and would deal with that phase of amoebic disease investi. gated at Calcutta during a period when the knowledge of hepatitis generally had made great advances. The work on the liver had been one of the most significant episodes in recent tropical medicine, although perhaps less dramatic than some discoveries, because more grạdual.

\section{A Review of Progress.}

At the beginning of the present century there was a good deal of confusion with regard to the relationship between dysentery and large single tropical liver abscess. The confusion was due to ignorance of the fact that there were two great classes of dysentery which, until recently, had been regarded as one definite disease. Those whose experience was in countries where the bacillary form prevailed denied its relation to liver abscess; while in Egypt and India, where amoebic dysentery was known to be common, observers had noted a relation. It was now understood that the prevailing type of dysentery in temperate climates was bacillary. In John Hunter's account of dysentery in the army in Jamaica in 1788 he did not mention liver abscess, and considered the dysentery to be the same as that described by Sydenliam as so prevalent in London in 1779-80. Recent investigation showed that to this day the bacillary type prevailed in Indian gaols, where the amoebic form was com paratively rare. In the Researches into the Causes, Nature, and Treatiment of the More Prevalent Diseases of India and of Warm Climates Generally, by James Annesley, of the Madras Medical Establishment, published in two volumes by the India Office in 1828 , it was clearly stated that liver abscess was secondary to dysentery. It was quite certain from these finely produced and illustrated volumes that amoebic dysentery was common in Madras early in the nineteenth century.

In the first three editions of his classical work on tropical diseases Manson described dysentery as a single entity; he pointed out that the term probably included a group of diseases, but that up to then the claims for different causative agents, whetlier bacterial or protozoan, were far from having been established. The confusion at the begiuning of the present century was well illustrated in the contradictory pature of articles on the subject in the first edition of Allbutt's System of Medicine. Altogether, it was not surprising that the amoeba was not accepted as the cause of the disease. Manson, in his early edition, stated that amoebae were present in more than half his cases, but this did not convince him of their causative powers. At the annual meeting of the British Medical Association in 1902 Andrew Duncan, who had then recently retired from the Indian Medical Service, opened a discussion on dysentery, and advanced the view that the amoeba had nothing to do with dysentery in any country as a causative agent. ${ }^{1}$ In Duncạu's view, large tropical liver

1 Biritish Medical Jodral, 1502, vol, ii. abscess did not bear. any specific relation to antecedent dysenteries, although small multiple abscesses did. Very similar views were also expressed at this time in a short editorial note in the Indian Medical Gazette. In spite of the valuable work of several.observers, especially Councilman and Kartulis, medical opinion at this time was against the theory of amocbic causation.

\section{Constant Presence of Amoebae.}

Sir Leonard Rogers went on to say that he had published his first paper on dysentery in 1902. It was based on two years' research he had conducted in Calcutta between April, 1900 , and tho end of 1902 , making use of all the clinical and post-mortem material he could obtain. The first point he had set out to determine was the frequency with which living amcebae might be found in large tropical liver abscess. It was easy to detect the amoebae post mortem in the walls by examining scrapings under the microscope, but much more difficult to detect them in the thick pus of such abscesses. In order to get a larger range of cases than was afforded by post-mortem examinations he arranged with his surgical colleagues, when they opened a liver abscess, to place some of the thick pus in one sterile-test tube, and in another the light scrapings from the wall of the cavity. Out of some 18 cases examined in this way, he found the amoeba in the pus in four, but in the scrapings of the wall he found it in every case except one. In 20 cases examined post mortem he again found the amoeba in the wall in every case except one, the exception being an instance in which the abscess had been opened and drained for fourteen days before the patient died. From this he concluded that amoebae were practically invariably present, a fact which he had verified in scores of later cases, the only exceptions being small and oncysted abscesses in which the amoebae seemed to have died out.

\section{Usual Sterility as regards Bacteria.}

He turned next to the question of the frequency of pus forming bacteria in large tropical abscess. Out of 24 cases in which cultures were made from the pus taken in sterile test tubes at the time of operation, 15, or 62 per cent., were sterile. The post-mortem examinations told the same story. In three out of five unopeued abscesses found post mortem there were no bacteria. In a later series of observations, out of a large number of consecutive cases he found 86 per cent. sterile when first opened. It was clear that the great majority of such abscesses were free from bacteria that could be cultivated, although few such abscesses remained sterile in a tropical climate after opening and drainage. His conclusion was that not only were amoebae constantly present, but other causal bacterial organisms were constantly absent. This indicated that Entamoeba histolytica was the causative organism in these cases of liver abscess.

\section{The Antecedent D.ysentery.}

The striking fact had not been explained that the proportion of cases of liver abscess to cases of dysentery in the British Army in India was 1 to 5 or 1 to 7 , while in Indian gaols it was one to several hundred. But if the prevailing type of dysentery was amoebic in the army, and bacillary in the gaols, the problem was solved; this was now known to be the case.

It had next to be determined what was the frequency of association between any form of dysentery and liver abscess. Among the cases of liver abscess which he had tabulated for the purpose of the lecture, in four there was no history of dysentery, but even in these, dysenteric ulcers were found post mortem, proving that the absence of clivical signs of previous dysentery did not exclude the presence of amoebic ulcers in the large bowel. In three other cases there had been a history of dysentery and no ulcers or scars were found post mortem, but only slight congestion; thus it was possible for antecedent dysentery to clear up without necessarily involving any ulceration before the patient died of liver abscess. In order to get accurate data it was essential to obtain both clinical and post.mortem records, and even then it was possible that a mild attack of bowel trouble might be overlooked clinically and leave no post-mortem evidences. The cases shown in his tables in which the clinical and post. mortem records were complete numbered 24 , and in $23^{\prime}$ (or over 95 per cent.) there were either clinical or post-mortem evidences of dysentery, while in 14 (or 58 per cent.) there were both clinical and post-mortem evidences. On adding certain older records which clinically were less complete, only 
9 per cent. failed to give a positive result either clinically or post mortem. He concluded that amoebic dysenteric ulcera. tion of the large bowel, often of a latent nature, always preceded the formation of large tropical liver abscess.

It was clear that the conclusions he had reached at the end of the first two years of his investigation were diametrically opposed to those of the distinguished tropical physician who opened the debate on dysentery at the annual meeting of the British Medical Association in 1902. In the following year, while at home on leave, he met Andrew Duncan, who with the utmost candour volunteered the statement that the paper recording these new investigations had completely upset almost everything he had said in that opening address. The paper, however, contained one error, corrected the following year, in its assumption that small multiple abscesses belonged to another category in respect to causation. Whatever the explanation might be, he was now certain that the majority of small multiple liver abscesses seen in Calcutta were amoebic in origin.

In 1913 he was able to supplement the data recorded in 1902 by an analysis of the results of forty-five necropsies which he had performed during the previous ten years; there was evidence of active amoubic dysentery in 78 per cent., and scars of former dysenteric lesions in 20 per cent. more, leaving only one case with no post-mortem evidence of dysentery. He recorded at the same time an analysis of careful clinical records of fifty cases of liver abscess during nine years, with a history of dysentery in 72 per cent., and of diarrhoea in 14 per cent., leaving only 14 per cent. with no history of lesions of the bowels.

\section{Lesions of the Bowel in Relation to Type of}

\section{Liver Abscess.}

A close examimation of the distribution and extent of the bowel lesions in various conditions threw much light upon this matter. The positions and extent of the lesions, from the lower ileum down to the rectum, as found in 96 consecutive post-mortem examinations, had been examined. In a number of cases of acute bacillary dysentery of less than one month's duration the whole length of the bowel was affected, including generally the lower part of the ileum. In a group of chronic bacillary dysenteries of a month or more in duration all except one showed the lesions limited to the lower half or two-thirds of the bowel. In acute amoebic dysentery, instead of continuous lesions, scattered lesions were found; they were very extensive, the large patches being met with throughout the greater length of the bowel. In chironic cases the lesions were less extensive. In five cases liver abscesses were present-in four of the five multiple small abscesses, and in the other a single small abscess; in all these cases the bowel lesions were extensive. In only one case-a case unusual in its clivical features-was there an exception to the rule that in multiple small liver abscesses there were very extensive lesions through nearly the whole length of the bowel. In cases of large liver abscess the lesions were less extensive; in some cases they were limited to the caecum, but in others they extended down to the ascending colon. In 13 out of 36 cases the lesions were absolutely limited to the caecum, and in 23 they were within narrow limits or there were only scars of old lesions which would not have given rise to any clinical symptoms of dysentery. In all these cases the dysentery was absolutely latent. Thus there was forthcoming an explanation of the former great stumbling.block to the recognition of tropical liver abscess as always secondary to dysentery-namely, the absence of clinical signs of that disease in a large number of patients suffering from the liver affection.

The black sloughs passed in the stools were absolutely diagnostic of amoebic dysentery, but beyond the ulcers the bowel in these cases was healthy. The appearance was very different in bacillary dysentery where, in the whole length of the bowel, there was no healthy part left.

\section{Large Single Liver Abscess.}

He dealt next with the method of formation of large single liver abscess. It was generally agreed that amoebae passed from the bowel wall to the liver through the portal vein. The earliest stage of small multiple abscesses of the liver was inflammation with clotting in the branches of the portal vein, which was followed by softening of the thin walls of the blood vessels and extension of the inflammatory process to the liver parenchyma. He believed the addition of a bacillary infection greatly assisted the breaking down of the vein walls. When multiple small abscesses arose in the liver as the result of a pure amoebic infection secondary to sloughing dysentery, the protozoan organisms had reached the liver in enormous numbers. The question of low one or more large abscesses developed as a result of portal infection raised otier considerations. In the early stage of his work he was inclincd to think that the frequency with which large abscesses occurred in the upper part of the liver, and the fact that in acute amoebic dysentery the protozoan organism frequently penetrated the whole thickness of the bowel wall, suggested the possibility that it passed in the lymph flow. It was, however, possible for liver abscess to be formed by direct extension from the bowel to the liver. Examination of microscopical sections of the walls convinced him that the abscesses were really formed within the liver, and not between it and the diaphragm. It appeared that the abscess, having once originated, developed within the organ. The single liver abscesses were seldom found in sloughing dysentery. It was evident that the development of large single abscesses as a class could not be explained save as due to infection from the bowel through the portal vein. It was necessary, how ever, to look to another and intermediate stage to explain the ultimate development of the fibrous-walled large abscess, which, however, was not very commonly met with. In the case of large ragged cavities without well-defined walls there was no definite limiting membrane, but the tissues around the irregular cavity were infiltrated by pus. Examination of microscopical sections demonstrated that the process was extending from the central cavity along the veins in which softening and clotting were taking place; in such cases. numerous amoebae were present, but in the great majority of cases no bacteria. It was clear that amoebae might reacl the liver in large numbers without suppuration in the organ necessarily taking place.

Taking all these facts into consideration, he supposed that in slight or latent amoebic colitis, from which large amoebic abscesses usually resulted, comparatively few amoebae reached the liver, the vast majority undergoing degenera tion in the vessels without being able to escape unless there was damage to the walls. In that case only a presuppurative amoebic hepatitis occurred. When the amoebae happened to reach some part of the liver in such numbers as to cause clotting of several contiguous small veins so as to interfero with the blood supply, and produce simple necrosis, allowing the escape of the amoebae into the soft tissues, an abscess resulted. The abscess continued to develop in concentric circles until, if the patient survived long enough, a fibrous capsule made its appearance, and the process then only went on by expansion of the cavity, without further destruction of tissue. Almost all forms of liver abscess were due to pure amoebic infections from the bowel, through the portal vein the number of amoebae varied. Whether or not an amoebic hepatitis went on to suppuration must of ten be in the balance, so that such causes as chills and alcoholism might easily precipitate the formation of an abscess, and early treatment avert it. Amoebic liver abscess was now much more easily preventable and curable than it was a few years ago, and future investigators would have little chance of obtaining such material as he had had in past years.

"My conclusions, which are now in agreement with those of more recent observers too numerous to mention, may be briefly summarized. The affection formerly known as tropical liver abscess, both in the acute multiple small form and the chronic large single form, is produced by infection through the portal vein with the Entamoeba histolytica, only occasionally assisted by bacteria, and is always secondary to antecedent amoebic ulceration of the large bowel, which is clinically active and acute in the multiple variety, but usually completely latent clinically in the more chronic single form while such abscesses never occur in relation to bacillary dysentery. These conclusions are a great advance on the view generally accepted two decades ago."

THE fifth Cuban National Medical Congress, held at Havana, was attended by more than 1,500 medical prac. titioners. It was divided into eight sections, of which five were devoted to medical and surgical subjects, one to pharmasy, one to odontology, and one to veterinary medicine.

IT is announced that the sum of $1,320,000$ dollars is to be available from the Sterling funds for the erection of a new building for the Yale medical school, to bc known as the Sterling Hall of Medicine. This building will contain a library, a lecture hall, administrative offices, rooms for tho teaching staff, and laboratories, with an animal house and a power house adjoining. 